\title{
TITLE:
}

\section{A new application of radiocarbon (14C) concentrations to stream food web analysis}

\section{AUTHOR(S):}

Ishikawa, Naoto F.; Uchida, Masao; Shibata, Yasuyuki; Tayasu, Ichiro

\section{CITATION:}

Ishikawa, Naoto F....[et al]. A new application of radiocarbon (14C) concentrations to stream food web analysis. Nuclear Instruments and Methods in Physics Research Section B: Beam Interactions with Materials and Atoms 2010, 268(7-8): 1175-1178

\section{ISSUE DATE:}

2010-04

URL:

http://hdl.handle.net/2433/109965

\section{RIGHT:}

(C) 2010 Elsevier; This is not the published version. Please cite only the published version.; この論文は出版社版でありません。引用の際には 出版社版をご確認ご利用ください。 


\section{TITLE}

A new application of radiocarbon $\left({ }^{14} \mathrm{C}\right)$ concentrations to stream food web analysis

\section{AUTHORS}

Naoto F. ISHIKAWA ${ }^{1, *}$, Masao UCHIDA ${ }^{2}$, Yasuyuki SHIBATA ${ }^{2}$ and Ichiro TAYASU ${ }^{1}$

\section{AFFILIATIONS}

${ }^{1}$ Center for Ecological Research, Kyoto University, 2-509-3 Hirano, Otsu, Shiga 520-2113, Japan

${ }^{2}$ Natinal Institute for Environmental Studies, 16-2 Onogawa, Tsukuba, Ibaraki 305-8506, Japan

${ }^{*}$ Corresponding author.

Naoto ISHIKAWA, Center for Ecological Research, Kyoto University

2-509-3 Hirano, Otsu, Shiga 520-2113, Japan

Tel: +81 77549 8240, Fax: +81 775498201

E-mail: naoto-i@ecology.kyoto-u.ac.jp 


\section{ABSTRACT}

We measured radiocarbon concentrations $\left(\Delta^{14} \mathrm{C}\right)$, together with stable isotope ratios $\left(\delta^{13} \mathrm{C}\right.$ and

$\delta^{15} \mathrm{~N}$ ) of aquatic animals, periphytic algae and particulate organic matter (POM) at upstream sites of two streams. We hypothesized that $\Delta^{14} \mathrm{C}$ values of organisms would be separated into two major carbon sources in streams: in-stream production (autochthonous production) and terrestrial detritus (allochthonous production). In fact, $\Delta{ }^{14} \mathrm{C}$ values of in-stream production were low, while those of terrestrial detritus were high. This indicates the difference in sources: the former reflects the $\Delta^{14} \mathrm{C}$ values of the dissolved inorganic carbon in the catchment, whereas the latter reflects the $\Delta^{14} \mathrm{C}$ value of present atmospheric $\mathrm{CO}_{2} \cdot \Delta{ }^{14} \mathrm{C}$ patterns of animals differed in each of the two streams, suggesting that the role of food web structure is critical for understanding the carbon dynamics of stream ecosystems. We present, for the first time, the potential use of radiocarbon $\left({ }^{14} \mathrm{C}\right)$ in the study of food webs in stream ecosystems.

PACS code: $87.23 . n$ (Ecology and evolution), 89.60._k (Environmental studies)

Key Words: stable isotope, ${ }^{14} \mathrm{C}$, carbon source, food web, stream ecosystems 


\section{INTRODUCTION}

Food webs of stream ecosystems are supported by two major carbon sources: inorganic carbon

fixed by algae or other aquatic plants (autochthonous production) and particulate organic matter (POM)

originating from terrestrial plant matter (allochthonous production). The relative importance of these two

carbon sources for food webs of stream ecosystems has been discussed in many studies over the past 30

years (e.g., [1]). To better understand the carbon dynamics of stream ecosystems, recent studies have used

stable carbon and nitrogen isotope ratios $\left(\delta^{13} \mathrm{C}, \delta^{15} \mathrm{~N}\right)$. As $\delta^{13} \mathrm{C}$ and $\delta^{15} \mathrm{~N}$ values can be used as indicators

of food source and trophic level of an organism, respectively, these isotopic dual plots can describe food

web structure $[2,3]$. However, periphytic algae attached to riverbed rocks, one of the most important

carbon source in stream ecosystems, often have fluctuating their $\delta^{13} \mathrm{C}$ values because photosynthetic

activity of algae varies both temporally and spatially (e.g., [4, 5]). From the perspective of carbon dynamics - including food webs - in stream ecosystems, it is often difficult to know whether animals depend on autochthonous production (e.g., inorganic carbon weathered from underground) or allochthonous production (e.g., organic carbon from terrestrial ecosystems).

In order to solve this problem, we made use of the constituent radiocarbon $\left({ }^{14} \mathrm{C}\right)$ concentration. In the field of biogeochemistry, $\Delta^{14} \mathrm{C}$ has recently begun attracting more attention worldwide. In Amazonian 
rivers, young terrestrial organic matter produced within 5 years was actively decomposed [6]. In sedimentary rock-based rivers, $\Delta{ }^{14} \mathrm{C}$ in particulate organic matter (POM) showed low values, suggesting that old carbon weathered from riverbed rocks significantly influences the carbon dynamics of river ecosystems [7]. Previous biogeochemical ${ }^{14} \mathrm{C}$ studies, however, have not paid attention to river food webs, which are one of the most important carbon transfer systems, and ${ }^{14} \mathrm{C}$ analysis has never been applied to ecological studies of river ecosystems. $\Delta{ }^{14} \mathrm{C}$ values are expected to be low in dissolved inorganic carbon (DIC) weathered from riverbed rocks and high in present atmospheric $\mathrm{CO}_{2}$. It is expected that animals in food webs based on periphytic algae, which produce organic carbon from DIC through photosynthesis, will show low $\Delta{ }^{14} \mathrm{C}$ values. In contrast, animals in food webs based on POM originating from terrestrial production (e.g., leaf litter) are expected to show high $\Delta^{14} \mathrm{C}$ values.

In this paper, we present the combined use of $\delta^{13} \mathrm{C}, \delta^{15} \mathrm{~N}$ and $\Delta{ }^{14} \mathrm{C}$ in food webs of stream ecosystems. In order to test the applicability of this method, we investigated the upstream food webs of two streams. If autochthonous and allochthonous carbon sources can be separated and discriminated using ${ }^{14} \mathrm{C}$, our novel method should be a promising tool in the study of food web structure in stream ecosystems. 


\section{MATERIALS AND METHODS}

In November of 2006 , this study was conducted at upstream sites of the Inukami $\left(35^{\circ} 2^{\prime} \mathrm{N}\right.$, $\left.136^{\circ} 4^{\prime} \mathrm{E}\right)$ and Seri $\left(35^{\circ} 2^{\prime} \mathrm{N}, 136^{\circ} 3^{\prime} \mathrm{E}\right)$ Rivers, which flow into Lake Biwa, central Japan (Fig. 1). Aquatic invertebrates and fishes were collected with a hand net. Periphytic algae attached to riverbed rocks (hereafter "periphyton") were collected with a toothbrush. POM (>1000 $\mu \mathrm{m})$ was collected with a surber net (mesh size $1000 \mu \mathrm{m})$. All animals were kept overnight in river water to clear digestive contents, freeze-dried for several days, and ground into fine powders. In the laboratory, periphyton and fish samples were kept overnight in $1 \mathrm{~N} \mathrm{HCl}$ solution to remove carbonate [8] and in chloroform-methanol 2:1 solution to remove lipids [9], respectively.

We measured $\delta^{13} \mathrm{C}, \delta^{15} \mathrm{~N}$ and $\Delta^{14} \mathrm{C}$ values of periphyton, POM, Stenopsyche marmorata (caddisfly, filter feeder), Calopterygidae spp. (damselfly, predator), Zacco temminckii (Cyprynidae, omnivore) and Oncorhynchus masou ishikawae (Salmonidae, predator). The values of S. marmorata and Calopterygidae spp. were measured as an average of compiled individuals, while those of Z. temminckii and O. ishikawae were measured as a single individual.

Stable isotope ratios (\%) were measured using an elemental analyzer EA1108 (Fisons) connected to a mass spectrometer (Delta S, Finnigan MAT) with an interface (Conflo II, Finnigan MAT). Data were 
corrected with two international standard substances (DL-Alanine; $\delta^{13} \mathrm{C}=-23.5 \%$, $\delta^{15} \mathrm{~N}=-1.7 \%$, Tyrosine; $\delta^{13} \mathrm{C}=-26.2 \%$ o, $\delta^{15} \mathrm{~N}=5.6 \%$ ). Standard deviations of the measurement in $\delta^{13} \mathrm{C}$ and $\delta^{15} \mathrm{~N}$ were $0.05 \%$ and $0.15 \%$, respectively. $\delta^{13} \mathrm{C}$ and $\delta^{15} \mathrm{~N}$ values are reported as relative to carbon in Peedee belemnite (PDB) limestone and nitrogen in air, respectively, using the following equation:

$$
\begin{gathered}
\delta^{13} \mathrm{C} \text { or } \delta^{15} \mathrm{~N}(\%)=\left(\left(R_{\text {sample }}-R_{\text {standard }}\right) / R_{\text {standard }}\right) \times 10^{3} \\
R={ }^{13} \mathrm{C} /{ }^{12} \mathrm{C} \text { or }{ }^{15} \mathrm{~N} /{ }^{14} \mathrm{~N}
\end{gathered}
$$

Graphitization for radiocarbon $\left({ }^{14} \mathrm{C}\right)$ measurement was performed following the method of [10].

${ }^{14} \mathrm{C}$ concentration was measured by an accelerator mass spectrometer (AMS) following the method of [11] and reported as a $\Delta^{14} \mathrm{C}$ value. ${ }^{14} \mathrm{C}$ concentration was corrected for the ongoing radioactive decay of international reference standard (oxalic acid) since AD 1950 and corrected for $\delta^{13} \mathrm{C}$ values of -25\% [12]. $\Delta{ }^{14} \mathrm{C}$ values (\%o) were reported with an error (\%o) of each analysis, which was within $7.5 \%$.

Using $\delta^{13} \mathrm{C}$ and $\Delta^{14} \mathrm{C}$ values, source contribution of periphyton to animals was estimated. We assumed that periphyton and POM are two carbon endmembers, calculated by following equations.

$$
\begin{gathered}
\text { Contribution }-\delta^{13} \mathrm{C}(\%)=\left(\delta^{13} \mathrm{C}_{\text {animal }}-\delta^{13} \mathrm{C}_{\mathrm{POM}}\right) /\left(\delta^{13} \mathrm{C}_{\text {periphyton }}-\delta^{13} \mathrm{C}_{\mathrm{POM}}\right) \times 10^{2} \\
\text { and } \\
\text { Contribution- } \Delta^{14} \mathrm{C}(\%)=\left(\Delta^{14} \mathrm{C}_{\text {animal }}-\Delta^{14} \mathrm{C}_{\mathrm{POM}}\right) /\left(\Delta^{14} \mathrm{C}_{\text {periphyton }}-\Delta^{14} \mathrm{C}_{\mathrm{POM}}\right) \times 10^{2}
\end{gathered}
$$


The animal of which contribution value was calculated as more than $100 \%$ and less than $0 \%$ was regarded as having $100 \%$ and $0 \%$, respectively.

\section{RESULTS}

$\delta^{13} \mathrm{C}$ values of periphyton were higher than those of POM in both streams studied (Fig. 2a, and b).

$\delta^{13} \mathrm{C}$ values of animals were located between these two carbon sources caused by isotopic mixing effects.

$\delta^{15} \mathrm{~N}$ values of organisms increased with trophic level caused by isotopic enrichment effects. The $\delta^{15} \mathrm{~N}$ values of animals of higher trophic level (fish) were higher than those of animals of lower trophic level (aquatic insect). $\Delta^{14} \mathrm{C}$ values of periphyton were lower than those of POM in both streams studied (Fig. 3a, and b). $\Delta^{14} \mathrm{C}$ values of animals were located between these two carbon sources caused by isotopic mixing effects. Animals in the Inukami River showed intermediate $\Delta^{14} \mathrm{C}$ values between periphyton and POM, while in the Seri River-except $O$. ishikawae-showed particularly low $\Delta^{14} \mathrm{C}$ values (Fig. $3 \mathrm{~b}$ ).

Contribution $-\delta{ }^{13} \mathrm{C}$ and Contribution $-\Delta^{14} \mathrm{C}$ values of $S$. marmorata, Calopterygidae spp. and $Z$. temminckii showed that both of periphyton and POM contributed to the diets of animals in the Inukami River (Table 1). In the Seri River, on the other hand, Contribution- $\delta^{13} \mathrm{C}$ values showed that both of periphyton and POM contributed to the diets of animals, while Contribution $-\Delta^{14} \mathrm{C}$ values showed that 
only periphyton contributed to the diets of animals (except $O$. ishikawae). O. ishikawae showed extremely high $\delta^{13} \mathrm{C}$ and $\delta^{15} \mathrm{~N}$ values, suggesting that this animal depended on different resources probably because they were fed artificially.

\section{DISCUSSION}

The $\Delta{ }^{14} \mathrm{C}$ values of periphyton were low, reflecting the signal of old carbon weathered from underground sources, while those of POM were high, reflecting the signal of new carbon from atmospheric $\mathrm{CO}_{2}$ (Fig. 3a, and b). $\Delta{ }^{14} \mathrm{C}$ values of animals were intermediate, indicating that carbon of different ages is intermingled in stream ecosystems. Although $\Delta{ }^{14} \mathrm{C}$ values of periphyton and POM in both streams showed similar patterns, $\Delta{ }^{14} \mathrm{C}$ values of animals from each stream showed different patterns (Fig. 3a, and b). Previous studies have regarded river organisms as pools of organic matter (e.g., [7]), neglecting the carbon transfer within food web structure. Our results showed that local food webs were not simple pools of organic matter and that there were several carbon transfer pathways through trophic levels within stream food webs.

Contribution- $\delta{ }^{13} \mathrm{C}$ and Contribution- $-{ }^{14} \mathrm{C}$ values of the same species or genera varied in both of streams studied (Table 1). In the Seri River, food web structure estimated by $\Delta^{14} \mathrm{C}$ values was different 
from that of $\delta^{13} \mathrm{C}$ values. One of the reasons that caused difference between the two estimations may be carbon isotopic heterogeneity of periphyton among microhabitats of stream ecosystems. In general, periphytic algae usually showed spatial variation in their $\delta^{13} \mathrm{C}$ values, depending on their photosynthetic activity [13]. High spatial heterogeneity of stream microhabitats characterized by canopy cover or current velocity should be considered to evaluate carbon isotopic fractionation through photosynthesis $([4,14])$. The $\delta^{13} \mathrm{C}$ value of autochthonous production varies depending on carbon source and fractionation, while the $\Delta{ }^{14} \mathrm{C}$ value of autochthonous production depends only on carbon source because the $\Delta^{14} \mathrm{C}$ value is corrected for by $\delta^{13} \mathrm{C}[12]$. In the context of food web analysis using isotopic technique, previous studies suggested that the $\delta^{13} \mathrm{C}$ value is limited to use in microhabitat scale [5]. The $\Delta^{14} \mathrm{C}$ value, on the other hand, is expected to integrate microhabitat's fluctuation and to be used for analysis of food webs in a larger scale (i.e., reach scale or drainage scale). Further studies are required to elucidate the relationship between heterogeneity of $\Delta^{14} \mathrm{C}$ values of periphyton and environmental properties (e.g., light intensity and current velocity) among various scales of stream ecosystems.

In conclusion, our results indicated that the $\Delta{ }^{14} \mathrm{C}$ method is effective in differentiating carbon sources in food webs of stream ecosystems because autochthonous and allochthonous carbon sources could be clearly discriminated. Furthermore, the results of this study suggested an applicability of $\Delta^{14} \mathrm{C}$ 
values as well as stable isotope ratios $\left(\delta^{13} \mathrm{C}\right.$ and $\left.\delta^{15} \mathrm{~N}\right)$ to the analysis of food web structure and carbon transfer in stream ecosystems.

\section{ACKNOWLEDGEMENTS}

We are grateful to Dr. F. Hyodo for various discussions and Dr. C. Yoshimizu for measuring stable isotope ratios. Associate Prof. M. Yoneda, Dr. T. Kobayashi, H. Uno and R. Suzuki measured ${ }^{14} \mathrm{C}$ at NIES TERRA. N.F.I. was supported by the Research Fellowships of the Japan Society for the Promotion of Science for Young Scientists. This research was supported by the Ministry of Education, Culture, Sports, Science and Technology: Grant-in-Aid for Young Scientists (A) (No.19681002) to I.T. 


\section{REFERENCES}

[1] R.L. Vannote, G.W. Minshall, K.W. Cummins, J.R. Sedell, C.E. Cushing, Can. J. Fish. Aquat. Sci. 37

(1) (1980) p.130-137

[2] M.J. Vander Zanden, J.B. Rasmussen, Ecology 80 (4) (1999) p.1395-1404

[3] J.C. Finlay, S. Khandwala, M.E. Power, Ecology 83 (7) (2002) p.1845-1859

[4] J.C. Finlay, M.E. Power, G. Cabana, Limnol. Oceanogr. 44 (5) (1999) p.1198-1203

[5] R. Zah, P. Burgherr, S.M. Bernasconi, U. Uehlinger, Freshwater Biology 46 (2001) p.871-882

[6] E. Mayorga, A.K. Aufdenkampe, C.A. Masiello, A.V. Krusche, J.I. Hedges, P.D. Quay, J.E. Richey,

T.A. Brown, Nature 436 (28) (2005) p.538-541

[7] P.A. Raymond, J.E. Bauer, N.E. Caraco, J.J. Cole, B, Longworth, S.T. Petsch, Marine Chemistry 92

(2004) p.353-366

[8] B. Fry, Marine Biology 79 (1984) p.11-19

[9] J. Folch, M. Lees, G.H. Sloane Stanley, J. Biol. Chem. 226 (1) (1957) p.497-509

[10] H. Kitagawa, T. Masuzawa, T. Nakamura, E. Matsumoto, Radiocarbon 35 (2) (1993), p.295-300

[11] M. Uchida, Y. Shibata, M. Yoneda, T. Kobayashi, M. Morita, Nucl. Instr. and Meth. B 223-224

(2004) p.313-317 
[12] M. Stuiver, H. Polach, Radiocarbon 19 (1977) p.355-363

[13] R. L. France, Can. J. Fish. Aquat. Sci. 53 (1996) p.1916-1919

[14] H. Doi, Y. Takemon, T. Ohta, Y. Ishida, E. Kikuchi, Marine and Freshwater research 58 (2007)

p. $811-817$

\section{FIGURE CAPTIONS}

Figure 1

Study sites.

Figure 2

$\delta^{13} \mathrm{C}$ and $\delta^{15} \mathrm{~N}$ maps of upstream of Inukami River (a) and Seri River (b). periphyton, POM, $S$. marmorata (caddisfly), Calopterygidae spp. (damselfly), Z. temminckii (Cyprynidae) and O. ishikawae

(Salmonidae) are shown. The error bar of data of periphyton indicates standard deviation of replicates

$(N=4)$. Each plot is the value of single individual or the average of assembled individuals.

Figure 3

$\Delta^{14} \mathrm{C}$ and $\delta^{15} \mathrm{~N}$ maps of upstream of Inukami River (a) and Seri River (b). periphyton, POM, $S$. marmorata (caddisfly), Calopterygidae spp. (damselfly), Z. temminckii (Cyprynidae) and O. ishikawae 
(Salmonidae) are shown. The error bar of data of periphyton indicates standard deviation of replicates

$(N=4)$. Each plot is the value of single individual or the average of assembled individuals. 
Table 1

Periphyton and POM contribution to animals was provided as percentage calculated by $\delta^{13} \mathrm{C}$ and $\Delta^{14} \mathrm{C}$

values. Asterisks $(*)$ indicate that $O$. ishikawae might depend on different resources.

\begin{tabular}{cccccc}
\hline & \multirow{2}{*}{ River } & \multicolumn{2}{c}{ Contribution- $\delta^{13} \mathrm{C}(\%)$} & \multicolumn{2}{c}{ Contribution- $\Delta^{14} \mathrm{C}(\%)$} \\
\cline { 3 - 6 } & Periphyton & POM & Periphyton & POM \\
\hline \multirow{2}{*}{ Stenopsyche marmorata } & Inukami & 58 & 42 & 62 & 38 \\
& Seri & 100 & 0 & 100 & 0 \\
Calopterygidae spp. & Inukami & 52 & 48 & 76 & 24 \\
Zacco temminckii & Seri & 70 & 30 & 100 & 0 \\
Oncorhynchus masou ishikawae & Inukami & 67 & 33 & 44 & 56 \\
\hline
\end{tabular}


Figures

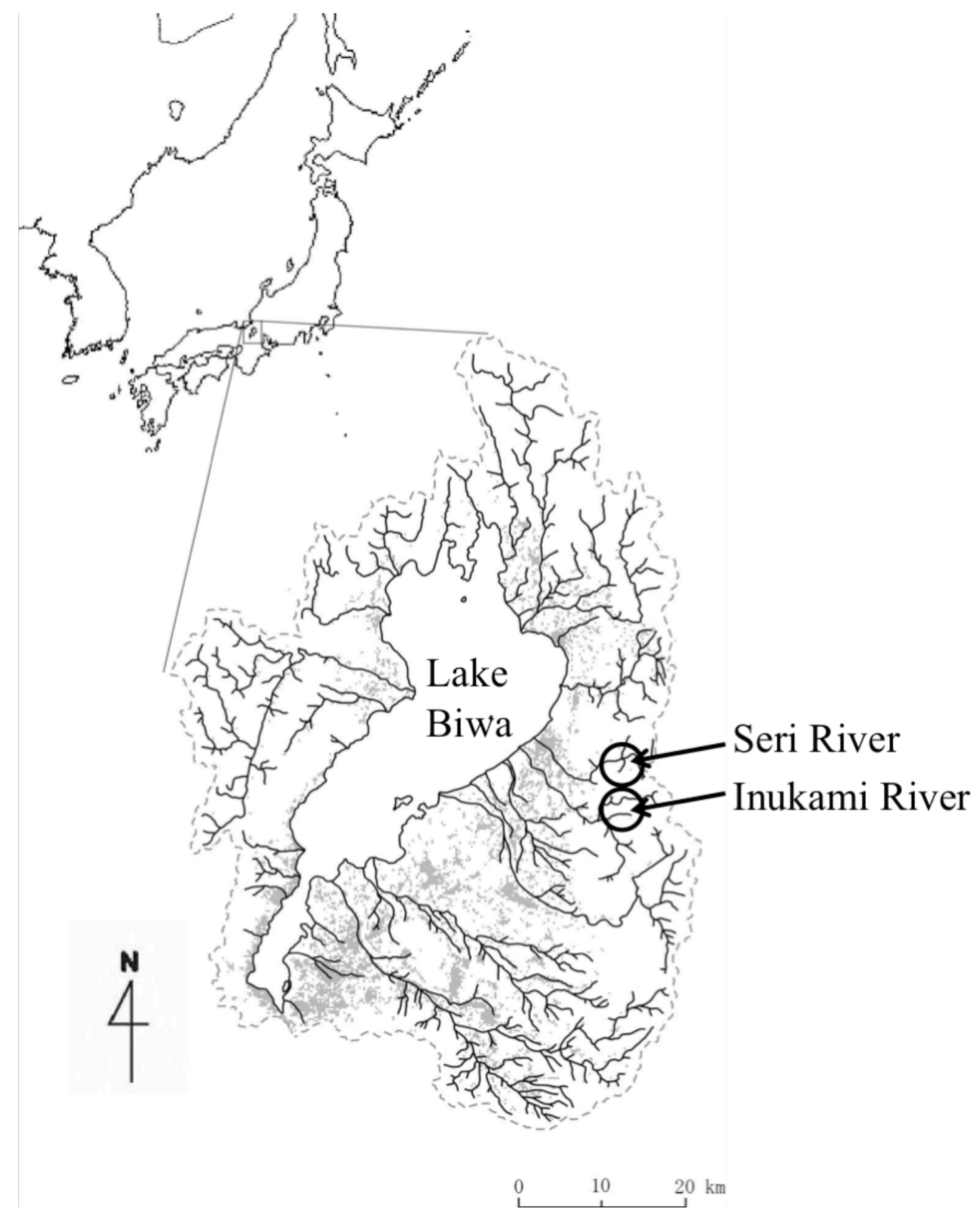

Figure 1 


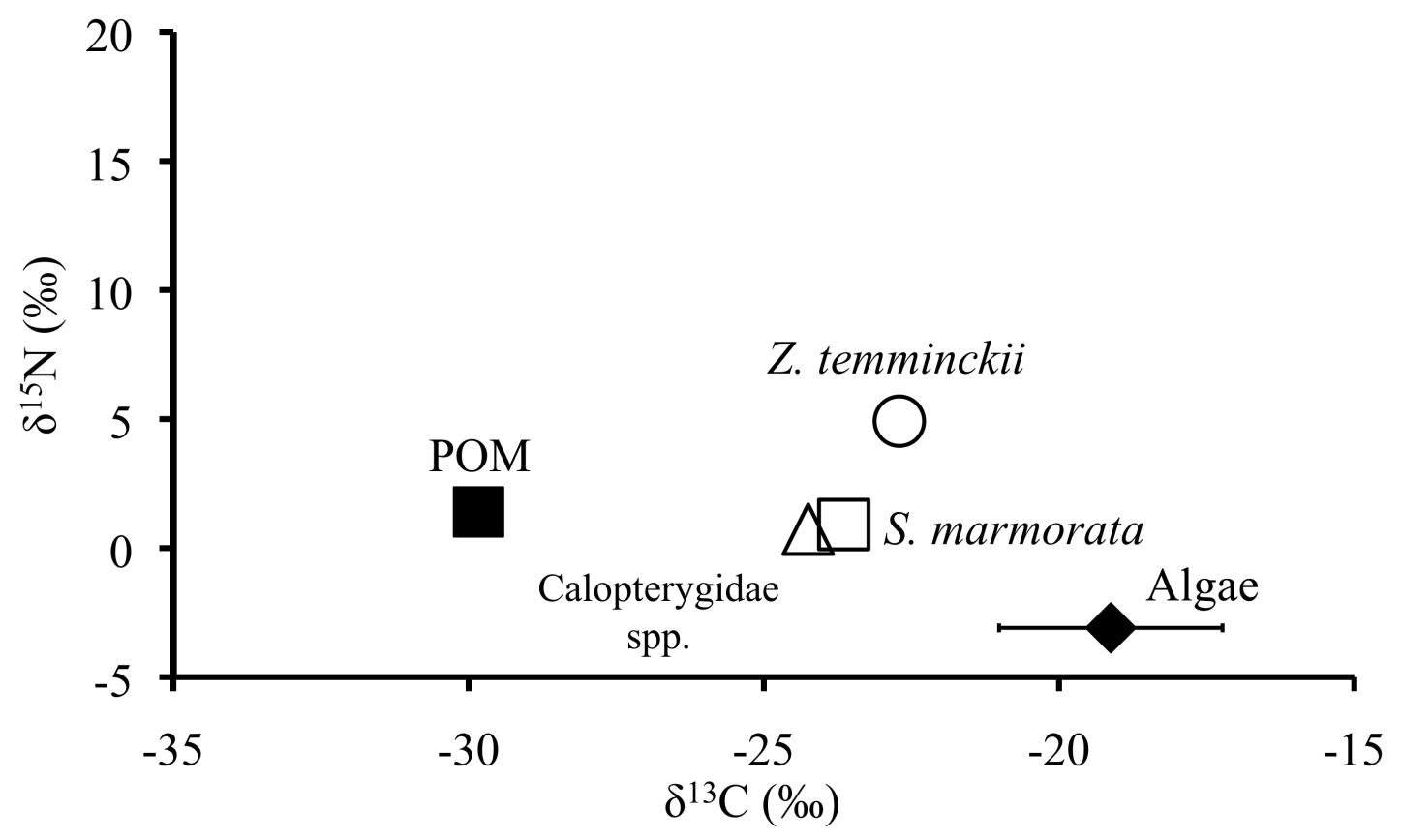

Figure 2a 


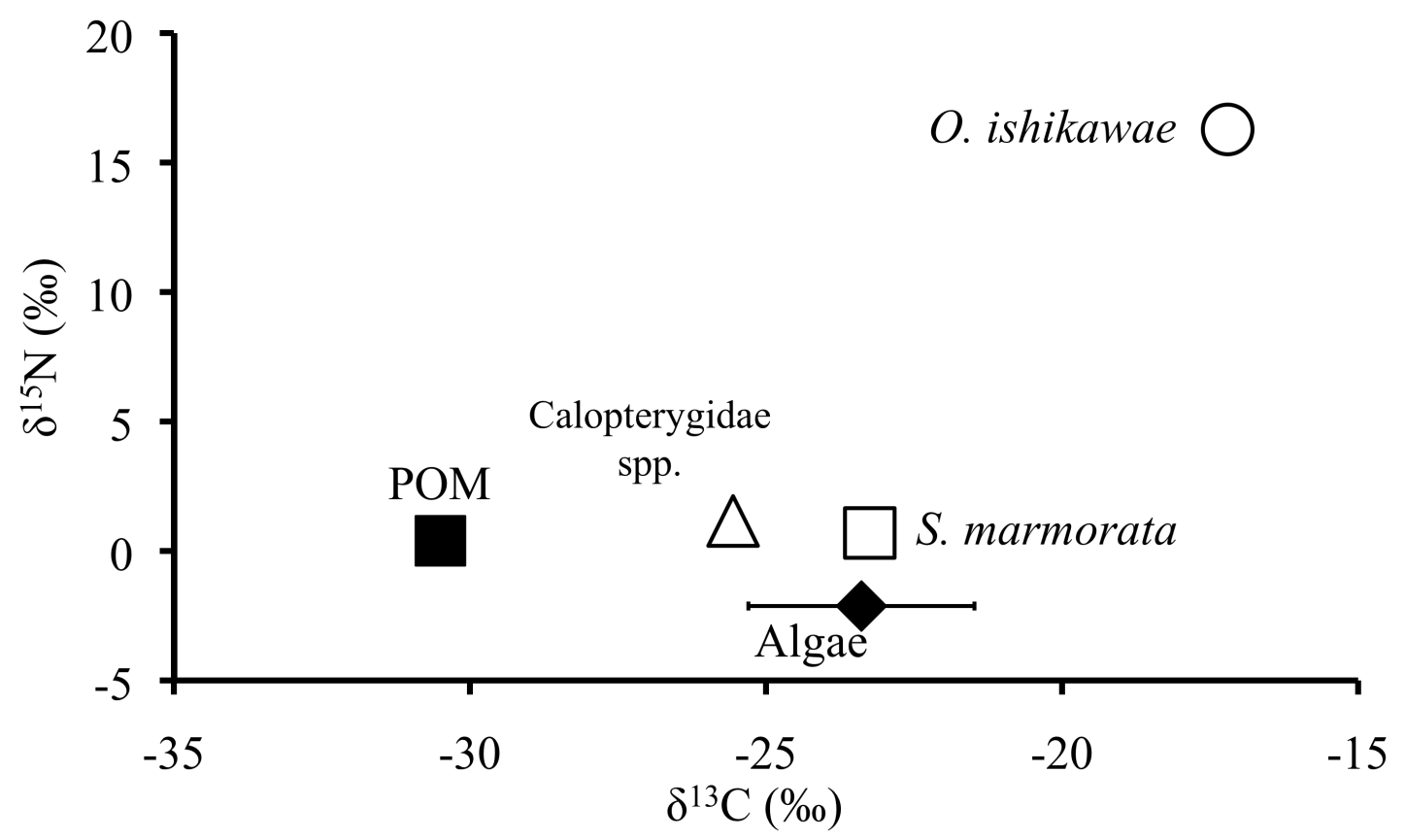

Figure 2b 


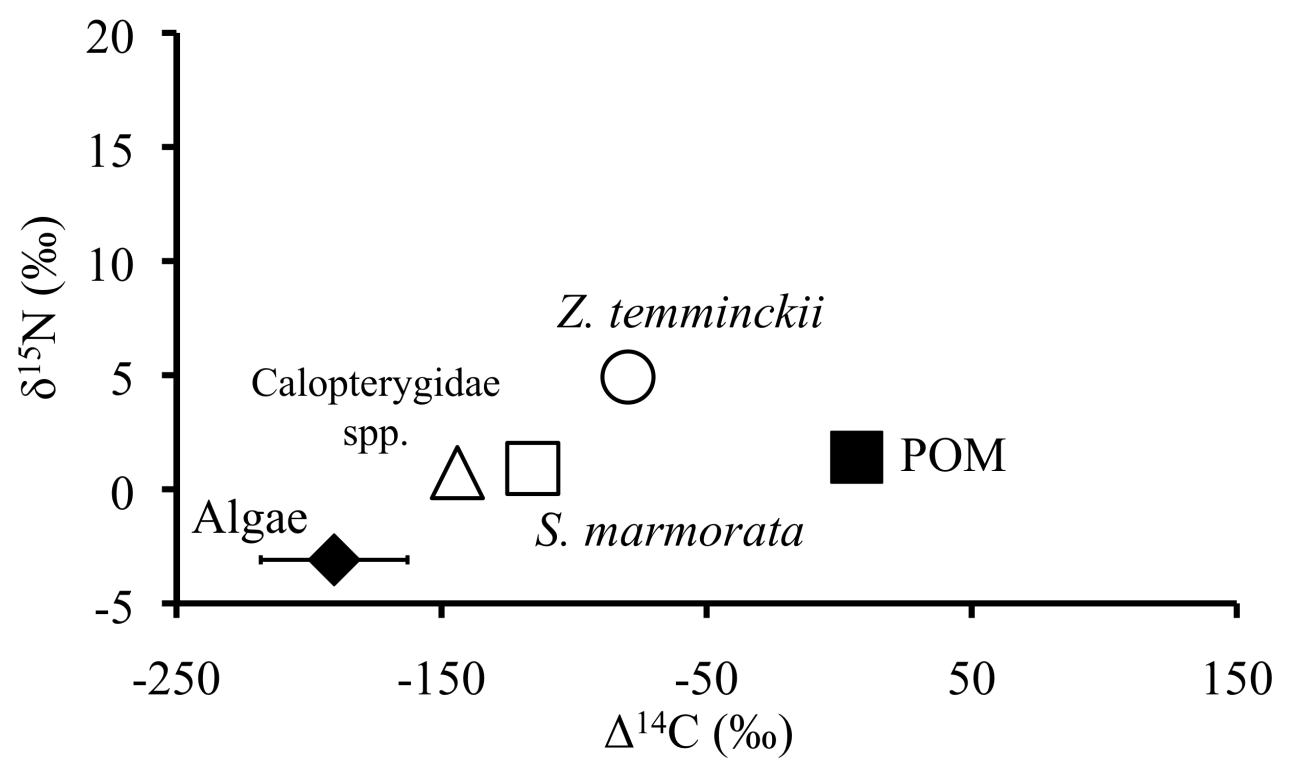

Figure 3a 


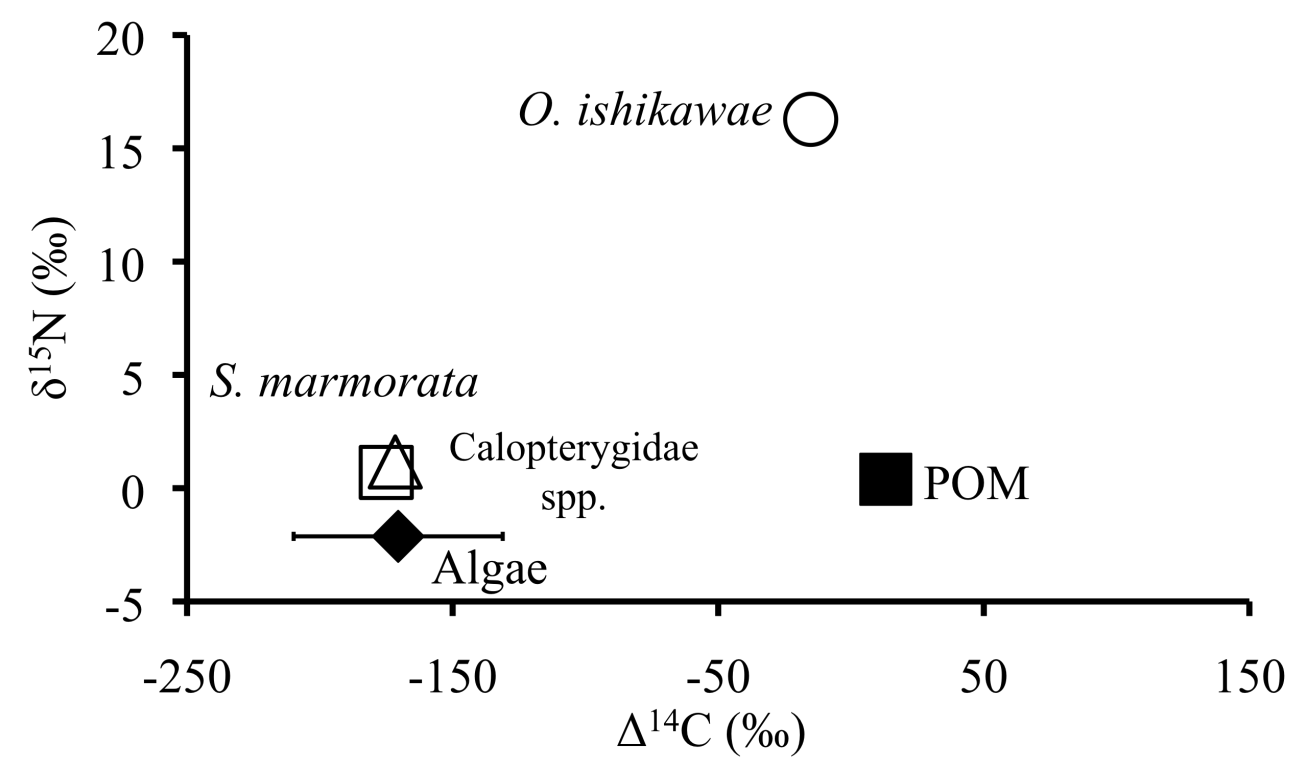

Figure $3 b$ 